\title{
Automation of diesel fuel consumption accounting on a special self-propelled rolling stock of Russian Railways
}

\author{
Alexander Mitrofanov ${ }^{1}{ }^{*}$, Vitaly Asabin ${ }^{1}$, and Andrey Peshkov ${ }^{1}$ \\ ${ }^{1}$ Samara State University of Railway Transport, Svoboda Street, 2a, Samara, 443063, Russia
}

\begin{abstract}
The article provides the results of a study to assess the effectiveness of automation of diesel fuel consumption accounting for a certain type of special self-propelled rolling stock of the company Russian Railways. The main current provisions of the fuel consumption assessment are considered. It is proposed to supplement the provisions on the adjustment of fuel consumption standards by identification methods. The identification method includes monitoring actual values, performance indicators, rolling stock mileage and fuel consumption forecasts. The analysis showed that the efficiency of fuel consumption automation can be as high as $30 \%$. The effect is achieved by fulfilling the forecast fuel consumption standards and eliminating unauthorized fuel overruns.
\end{abstract}

\section{Introduction}

The current task for the territorial branches of the company Russian Railways is to increase fuel efficiency on a special self- propelled rolling stock (SSPS) One of the ways to increase fuel efficiency the SSPS diesel engines are to automate fuel consumption accounting.

Basic automation equipment includes fuel consumption control sensors installed in the diesel fuel system.

The data measured by fuel consumption sensors is monitored through electronic microprocessor systems, which are installed in the cockpit of SSPS drivers.

Processing of fuel consumption data for the SSPS, rationing of fuel for travel and efficiency assessment is carried out at stationary fuel release points or in the fuel departments of the territorial branches of The Russian Railways.

To date, the scientific literature has considered several major areas of fuel efficiency improvement.

The first direction is to include works that define strategic approaches to control the consumption of diesel fuel [1]. The work of this area includes research on both hardware and software to account for fuel consumption.

The second direction includes studies on the impact on fuel consumption and the level of operating costs of locomotives [2]. At the same time, an increase in the age of the locomotive fleet is considered as one of the main factors influencing. The study found that

\footnotetext{
* Corresponding author: almit77@mail.ru
} 
fuel consumption could increase to $2.75 \%$ per year. This area includes research to improve the efficiency of diesel engines by disabling part of the cylinders. Improvements in performance can range from 4 to $30 \%$.

The third significant area includes research on fuel regulation [3], as well as on the impact of diesel engines on pollution [4 - 10]. These works examine the operational and emission characteristics of an engine powered by a mixture of diesel and organic matter.

The fourth area includes research on the use of hydrogen gas in diesel engines using onboard batteries. The total efficiency of the power plant can be as high as $30 \%$ [11]. This area includes, for example, research on the operation of a diesel engine with a two-fuel mode of operation (Common Rai), equipped with an electronic control unit [12, 13]. .

As part of the implementation of all designated areas of research, automated diesel consumption systems are provided. The purpose of the study was to assess the impact of these systems on fuel consumption savings during the normal functioning of the SSPS. Accurate measurement of the actual fuel consumption allows to make adequate rationing, to reduce its consumption, including unsanctioned fuel consumption.

\section{Research methods}

According to the regulations of the Russian Federation with an indirect method of static measurements and an indirect method of measurements based on hydrostatic principle, the error of sensors to measure diesel fuel should be no more than $0.65 \%$. According to literature analysis, sensors with similar accuracy can be attributed to sensors described in the works of the $[14,15]$, such as KRAL Volumeter sensors. According to the information provided in the [14] sensors, with a sensor error of $0.5 \%$, the error of the entire automated accounting system can reach more than $10 \%$. Thus, with a sensor error of $0.65 \%$, the total error of automated fuel consumption measurement should be expected at $13 \%$. These calculations suggest that the formation of standards for diesel fuel consumption of the SSPS on the basis of its actual measurements can be made with the same error.

The second objective of the study was to assess the effectiveness of automation of diesel fuel consumption and the use of the method of identifying fuel overruns, including unauthorized. This paper presents the results of the analysis of fuel consumption accounting for the type: MLT-6 - motorvehicle lift loading transport. This type of motor ized spree is widely used in the activities of the "Infrastructure Direction" at the Russian Railway's subsidiaries.

Fuel consumption data were obtained from studies conducted in two phases:

- with the equipment of the SSPS with fuel consumption automation devices (2016);

- with automation devices unstaffed by the SSPS (2019).

Fuel consumption studies were assessed during the normal operation of the SSPS in its regular regimes: working mode, idling mode, transport mode. Automation devices used "KVARTA" kits developed by Electromechanics (http://www.elmeh.ru) that were equipped with SSPS in 2016. According to the developer, the "KVARTA" complex allows to assess the accuracy of fuel consumption with a margin of error of no more than $0.67 \%$.

Statistical analysis and identification models for assessing technological performance were used to improve the analysis methods for assessing the efficiency of diesel fuel consumption at the SSPS processes [16]. Diesel consumption efficiency can only be assessed by comparing actual fuel consumption with the established fuel consumption norms for this type of SSPS and for specific operating conditions. Obviously, the positive efficiency will depend both on the accuracy of the measurement of actual fuel consumption and on the adequacy of the established consumption norms. According to the regulatory document "The method of planning and rationing fuel consumption for special rolling stock in the Russian Railways, No. 2464p approved in 2007, the concept of "fuel consumption 
rate" is an estimated amount of fuel, necessary to carry out the planned amount of work according to the established technological modes.

Fuel consumption rate $b_{i}$ for the $i$-technological regime, it is calculated in kilograms of diesel fuel, measured in $\mathrm{kg}$ for one hour of work of the SSPS. Thus, based on operating modes, the SSPS distinguish the time of operating modes of: the SSPS $H_{w m}$ - hour working mode; $H_{i m}$ - hour idling mode; $H_{t r m}$ - hour transport mode. The sum of all modes is defined as $H_{\text {totm }}$ - hour in total mode. According to the above document, the fuel consumption rate for MLT-6 is determined by the formula:

$$
B_{M L T}=\left(b_{w m} \cdot H_{w m}+b_{i m} \cdot H_{i m}\right) \cdot K_{\tau},
$$

where is $b_{w m}$ - fuel consumption rate for working mode, $\mathrm{kg} / \mathrm{h}$;

$b_{i m}$ fuel consumption rate the SSPS for idling mode.

$K_{\tau}$ - adjustment factor, taking into account the impact of the projected temperature of $\mathrm{T}$ , ${ }^{\circ} \mathrm{C}$ of the ambient air.

The methodology under consideration for the type SSPS of study recommends the use of deterministic values in the calculations $b_{w m}=9,1 \mathrm{~kg} / \mathrm{h}, b_{i m}=6.3 \mathrm{~kg} / \mathrm{h}$.

The methodology does not provide for the rationing of the specific fuel consumption of the SSPS taking into account the transport mode. This may reduce the reliability of the Fuel Consumption (Norm), kg indicator. The disadvantages of the methodology considered should include fixed as static norms of specific fuel consumption, the absence for a number of SSPS, including for MLT-6, the consumption norms for the transport mode.

The identified shortcomings of the above rationing approach can be partially corrected by the use of "Methods of rationing, planning and analysis of diesel fuel use on the SSPS based on onboard systems № 3060p, approved by Russian Railways in 2015.

In the methodology of the rate of specific fuel costs $b_{i}^{N}$ in the $i$ mode of operation, the SSPS is determined by statistics for the base period according to the formula:

$$
b_{i}^{N}=\left(\sum_{j} B_{j}^{F}\right) /\left(\sum_{j} H_{j}^{F}\right)
$$

where $B_{j}^{F} \quad H_{j}^{F}$ - actual fuel consumption, $\mathrm{kg}$ and running time, hour, respectively in imode based on the results of $k$ trips $j=1 \div k$ SSPS. Fuel consumption rate $B_{j}^{N}$ is defined as

$$
B_{j}^{N}=\sum_{i}\left(b_{i}^{N} \cdot H_{i}^{P l}\right)
$$

where $H_{i}^{P L}$ - scheduled opening time, hour, SSPS in $j$ - th train in $i$ mode, including in transport mode. Thus, the methodology in question proposes to calculate the rate of diesel fuel consumption $B_{j}^{N}$ in $j$ - th train based on the expression

$$
B_{j}^{N}=\left(b_{w m}^{N} \cdot H_{w m}^{P L}+b_{i m}^{N} \cdot H_{i m}^{P L}+b_{t r m}^{N} \cdot H_{t r m}^{P L}\right)
$$


where $b_{t r m}^{N}$. is the fuel consumption rate for the transport mode.

The disadvantages of the methods considered include the limited number and types of factors used for rationing. Only opening hours in SSPS modes are used as factors and do not use, for example, Run, $\mathrm{km}$. As a result of the above limitation, multi-factor simulation indicators of diesel consumption are not used. On the basis of previous studies, the authors proposed improvements in the method of rationing and planning of diesel fuel consumption on the SSPS by identification methods. The main provisions and stages of the methodology:

1) Fuel consumption rate $B_{j}^{N}$ for stationary volumes of work are formed on the basis of monitoring, actual fuel costs $B_{j}^{F}$ in travel.

The composition of $m$ operational $\boldsymbol{X}_{\boldsymbol{\sigma}}$ factors that affect the level of actual fuel consumption $B_{j}^{F}$ is formed. These factors include a variety of indicators that are investigated in the work of the fuel efficiency assessment. Such indicators include, for example, the mileage indicator - Run, which is not used in known methods.

2) Establishes the kind of operator of the relationship $\boldsymbol{A}$ (linear, non-linear) between $B_{j}^{F}$ and $\boldsymbol{X}_{\boldsymbol{g}}$, taking into account their stochastic nature:

$$
\boldsymbol{B}_{j}^{F}=\boldsymbol{A}\left(\boldsymbol{X}_{\jmath_{1}}, \boldsymbol{X}_{\mathrm{v}_{2}}, \ldots, \boldsymbol{X}_{\mathfrak{i}_{i}}, \ldots \boldsymbol{X}_{\boldsymbol{m}}\right)+\boldsymbol{\xi},
$$

where $\boldsymbol{\xi}$ is the stochastic component of $B_{j}^{F}$, formed by factors that are not taken into account.

A significant advantage of the technique over the known is the possibility of using in general non-linear types of operators.

3) Operator $\boldsymbol{A}$ parameters are being identified. In a private case, when linear it is related to $\boldsymbol{X}_{\boldsymbol{9}}$ factors, the operator of $\boldsymbol{A}$ is advisable to present in the form of a linear multifactorial equation of regression of the species:

$$
\boldsymbol{B}_{j}^{\boldsymbol{F}}=a_{0}+b_{1} \cdot \boldsymbol{X}_{\mathrm{\jmath}_{1}}+b_{2} \cdot \boldsymbol{X}_{\mathrm{\jmath}_{2}}+\ldots+b_{i} \cdot \boldsymbol{X}_{i}+\ldots+b_{m} \cdot \boldsymbol{X}_{\mathrm{s}_{m}}+\xi,
$$

where $a_{0}$ is free member of the regression equation; $b_{1}, b_{2}, \ldots b_{i}, \ldots b_{m}$ model parameters for "explaining" performance.

4) Based on calculated parameters $a_{0}$ and $b_{1}, b_{2}, \ldots b_{i}, \ldots b_{m}$ in the specified planned $\boldsymbol{X}_{\boldsymbol{g}_{i}}^{\boldsymbol{P L}}$ values, the values of fuel consumption $B_{j}^{N}$ on trips are modeled:

$$
\boldsymbol{B}_{j}^{N}=a_{0}+b_{1} \cdot \boldsymbol{X}_{\mathbf{9}_{\boldsymbol{I}}}^{P L}+b_{2} \cdot \boldsymbol{X}_{\mathbf{9}_{2}}^{P L}+\ldots+b_{i} \cdot \boldsymbol{X}_{\boldsymbol{i}}^{P L}+\ldots+b_{m} \cdot \boldsymbol{X}_{\boldsymbol{g}_{\boldsymbol{m}}}^{\boldsymbol{P L}}+\xi
$$

Accuracy is estimated by the average absolute error - MAPE assessment (Mean Absolute Percentage Error) when comparing model $B_{j}^{N}$ and actual consumption standards $B_{j}^{F}$ in diesel

$$
M A P E=\frac{1}{k} \sum_{j=1}^{k}\left|\frac{B_{j}^{N}-B_{j}^{F}}{B_{j}^{F}}\right| \cdot 100 \%
$$


The quality of the model is considered excellent if MAPE is $10 \%$. If $10 \%$ of MAPE is $20 \%$, the quality of the model is considered good.

\section{Experimental data and results}

The analysis of fuel consumption monitoring results at the MLT-6 was based on measurements taken by Electromechanics company in 2016. The data were obtained from 40 visits over a period of two months (table 1). The research has monitored the actual fuel costs - Fuel Consumption (Fact), kg. and only one operating indicator - Run, km per trip. The actual consumption was compared to the fuel consumption rate - Fuel Consumption (Norma), kg.

Table 1. Data on actual and regulatory fuel consumption of MLT-6 for automation by Electromechanics data in 2016.

\begin{tabular}{|}
\begin{tabular}{|c|c|c|c|c|c|}
\hline Travel date & Run, km & $\begin{array}{c}\text { Fuel } \\
\text { Consumption } \\
\text { (Fact), kg }\end{array}$ & $\begin{array}{c}\text { Fuel Consumption } \\
\text { (Norma), kg }\end{array}$ & $\begin{array}{c}\text { Savings (-)/ } \\
\text { overspend } \\
(+), \mathrm{kg}\end{array}$ & $\%$ Savings \\
\hline 01.08 .2016 & 90,9 & 36,0 & 40,5 & $-4,5$ & $-12,5 \%$ \\
\hline 03.08 .2016 & 58,7 & 34,0 & 51,3 & $-17,3$ & $-50,9 \%$ \\
\hline 04.08 .2016 & 93,5 & 32,0 & 56,5 & $-24,5$ & $-76,6 \%$ \\
\hline 05.08 .2016 & 3,3 & 24,0 & 33,7 & $-9,7$ & $-40,4 \%$ \\
\hline 08.08 .2016 & 1,9 & 4,0 & 9,4 & $-5,4$ & $-135,0 \%$ \\
\hline \multicolumn{7}{|c|}{} \\
\hline 28.09 .2016 & 156,0 & 74,0 & 83 & -9 & $-12,2 \%$ \\
\hline 29.09 .2016 & 196,6 & 71,0 & 76,4 & $-5,4$ & $-7,6 \%$ \\
\hline
\end{tabular}
\end{tabular}

According to the data provided, graphs of actual and normative fuel consumption were constructed in conjunction with Run (Fig. 1).

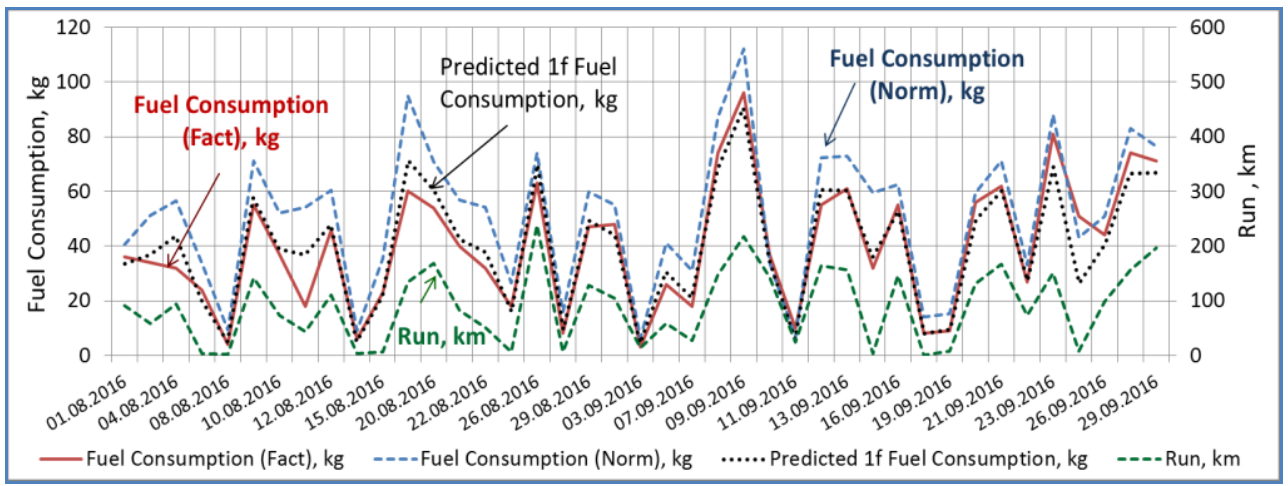

Fig. 1. Graphs of actual consumption and fuel consumption standards when automating accounting at the «KVARTA» complex for 2 months of 2016 engine-carrying MLT- 6.

Visual analysis of the graphs presented in Figure 1 shows a steady excess of the normalized indicators of Fuel Consumption (Norma), kg over actually measured - Fuel Consumption (Fact), kg. Statistical processing of the data showed that the average normative fuel consumption per trip is $(51.3 \mathrm{~kg})$ and is $28 \%$ higher than the actual (39.9 $\mathrm{kg})$.

The effect is achieved by automating fuel consumption accounting for the SSPS. The well-known methodology of Russian Railways from 2015 allows to adjust the specific values of fuel $b_{i}^{N}$ in different $i$-x operating modes based on expression (2). In the absence 
of data on actual fuel consumption $B_{j}^{F}$ and $H_{j}^{F}$ time, it is possible to adjust the normative values of $\boldsymbol{B}_{j}^{N}$ based on the construction of expression models (5), (6). Figure 2 shows that there is a high relationship between Run and Fuel Consumption (Norma) and Fuel Consumption (Fact) in the 2016 studies - R correlation ratios of more than 0,82 .

Based on the proposed identification method (5)-(7) it is possible to adjust the Fuel Consumption (Norma) indicator based on the construction of a two-factor model based on Fuel Consumption (Fact) and Run (Figure 2 b). In Figure 1, the adjusted expense is presented as Predicted 1f Fuel Consumption, kg. MAPE - estimates of this indicator is $15 \%$, which indicates the good quality of the model. Research to test the effectiveness of automation tools to account for fuel consumption has been continued in 2019.

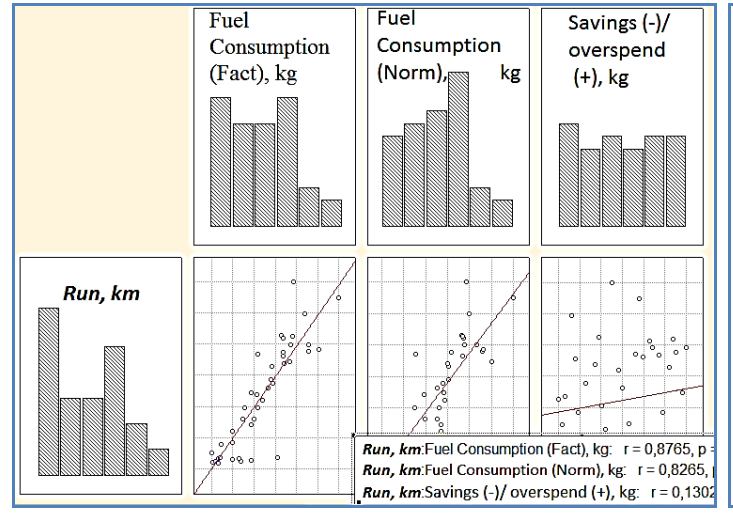

a)

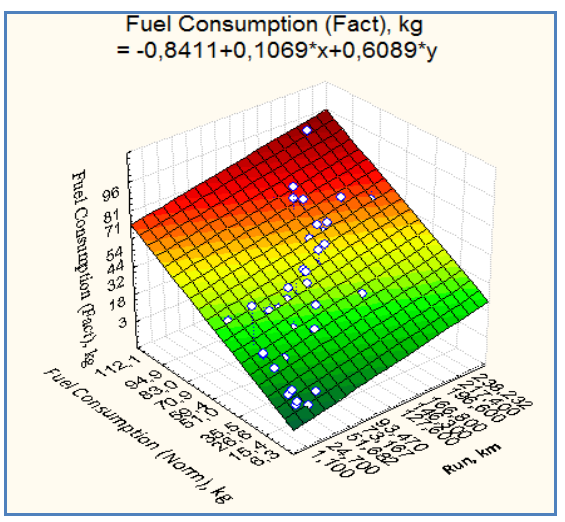

b)

Fig. 2. Results of statistical processing of fuel consumption MLT- 6 from 2016 data: a) the type of regression relationships and the value of correlation ratios; b) a two-dimensional model to adjust Fuel Consumption rationing (Norma).

By the time of the research, the automation equipment on the IPT-6 was dismantled. Fuel consumption and operating modes were monitored according to the AU-12 route sheets for the period of two months of 2019 (table.2). It was found that when the route sheets were filled, the actual figures were filled only as inteccly, which did not meet the requirements of the methodology and reduced the accuracy of monitoring. Fuel consumption values by type of work are defined as constant values for each trip поездки: $b_{w m}^{N}=11 \mathrm{~kg} / \mathrm{h}, \quad b_{i m}^{N}=6 \mathrm{~kg} / \mathrm{h}, b_{t r m}^{N}=11 \mathrm{~kg} / \mathrm{h}$. These values exceed the established method in working mode by at least $20 \%$, in transport mode by at least $100 \%$.

Table 2. Data on actual and regulatory fuel consumption of SSPS IPT-6 in 2019.

\begin{tabular}{|c|c|c|c|c|c|c|}
\hline Travel date & $\begin{array}{c}\text { Run, } \\
\mathrm{km}\end{array}$ & $\begin{array}{c}\text { Hour in } \\
\text { total } \\
\left(\mathrm{H}_{\text {totm }), \mathrm{h}}\right.\end{array}$ & $\begin{array}{c}\text { Fuel } \\
\text { Consumption } \\
(\text { Fact }), \mathrm{kg}\end{array}$ & $\begin{array}{c}\text { Fact } \\
\left(\mathrm{H}_{\mathrm{wm}}\right), \mathrm{h}\end{array}$ & $\begin{array}{c}\text { Fact } \\
\left(\mathrm{H}_{\text {im }}\right), \mathrm{h}\end{array}$ & $\begin{array}{c}\text { Fact } \\
\left(\mathrm{H}_{\text {trm }}\right), \mathrm{h}\end{array}$ \\
\hline 01.04 .2019 & 50 & 9 & 92 & 6 & 1 & 2 \\
\hline 02.04 .2019 & 100 & 10 & 103 & 6 & 1 & 3 \\
\hline
\end{tabular}

\begin{tabular}{|l|c|c|c|c|c|c|}
\hline 25.06 .2019 & 155 & 10 & 273 & 6 & 1 & 3 \\
\hline 26.06 .2019 & 250 & 9 & 92 & 4 & 1 & 4 \\
\hline
\end{tabular}

Grafics in Figure 3 according to Table 2 shows that the database's inflated values can be filled without system control. These Run values include data during periods: 02.06.2019 150km; 22.06.2019 - $170 \mathrm{~km} ; 26.06 .2019$ - $250 \mathrm{~km}$. 
The presence in the database of "emissions" - introduced inflated and uncontrolled fuel consumption values is evidenced by data during travel periods: 16.06 .2019 - $302 \mathrm{~kg}$; 25.06 .2019 - $272.5 \mathrm{~kg} ; 30.06 .2019$ - $236 \mathrm{~kg}$. This may indicate an unauthorized fuel overrun. Conclusions have been drawn about problems in the methodical provision of software means of keeping databases of route sheets of the AU-12 form.

A statistical analysis of the results of 60 MLT-6 trips without fuel flow automation showed that with the same amount of work, the average Fuel Consumption (Fact) average. $79.2 \mathrm{~kg}$. The formula (6) normative indicator gives an average estimate of $67 \mathrm{~kg}$.

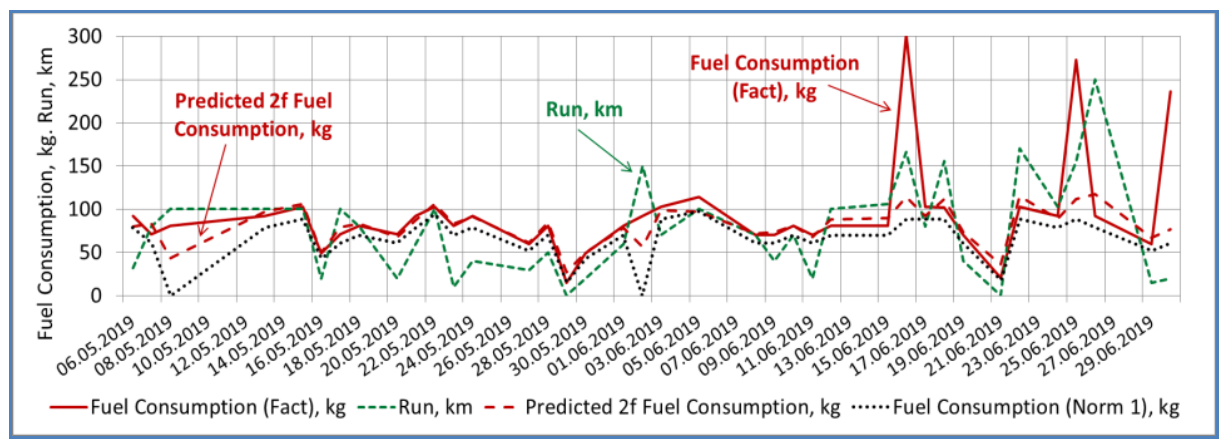

Fig. 3. Actual fuel consumption schedules of MLT-6 and operating performance for 2019.

Thus, the lack of automation in the SSPS can lead to fuel overruns of an average of 18 per cent or more over the period. Reducing fuel consumption can be achieved by determining the exact fuel consumption standards in the database and by controlling whether it meets actual fuel consumption value. In order to accurately construct fuel consumption norms based on the proposed identification method based on the multidimensional species model (6), it was necessary to assess the relationship between Fuel Consumption (Fact) and the modes of operation of the researched MLT-6. Figure 4a presented histograms of fuel consumption IPT- 6 in different modes, the type of regression relationships and the value of $\mathrm{R}$ correlation ratios between modes.

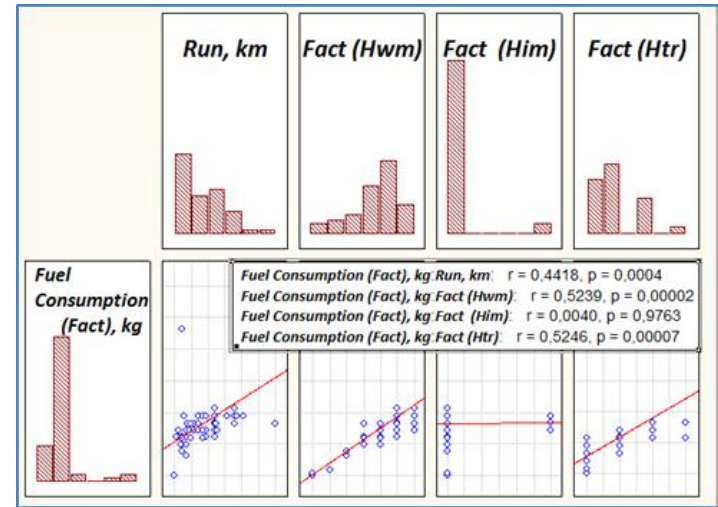

a)

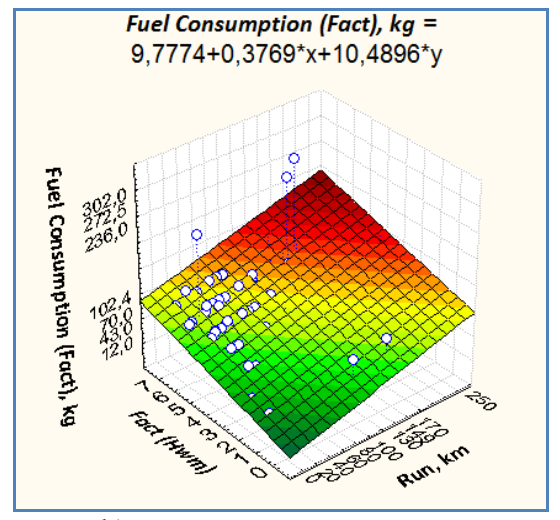

b)

Fig. 4. Results of statistical fuel consumption processing MLT- 6 by 2019 data: a) type of regression relationships and correlation $\$$ b) two-dimensional model to adjust Fuel Consumption rationing (Norma).

So the correlation ratio of Fuel Consumption (Fact) with the indicators. Hour working mode $\left(H_{w m}\right)$ and Hour transport mode $\left(H_{t r m}\right)$ is $\mathrm{R}=0,52$. The level of relationship with the hour idling mode is insignificant $\mathrm{R}=0,004$. Figure $4 \mathrm{~b}$ builds a two-factor regression 
model Fuel Consumption (Fact), which uses mileage indicators - Run and hour working mode- Fact $H_{w m}$ In this image, the indicators of the resulting model form a surface that interpolates the main field of measurement points. Fuel Consumption (Fact) values representing "emissions" are released from the operational interconnection system and are located at a considerable distance from the formed surface.

In general, if you have more performance, such as environmental or temperature, it is possible to build more accurate models of Fuel Consumption (Norma) indicator.

The method of selection of indicators in this multidimensional model consists of several stages. Figure 5 a shows a dendogram built by cluster analysis. The dendogram is a generalized scheme of correlations of the indicators studied.

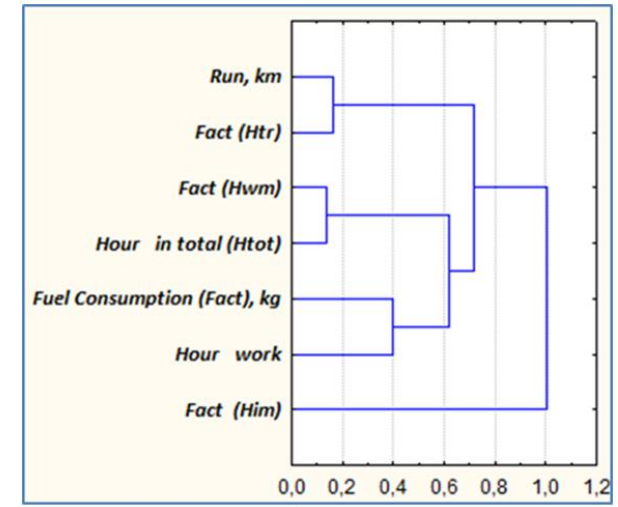

a)

\begin{tabular}{|c|c|c|c|c|c|c|}
\hline \multirow[b]{2}{*}{$N=41$} & \multicolumn{6}{|c|}{$\begin{array}{l}\text { Regression Summary for Dependent Variable: Fuel Consumption } \\
R=, 89909434 \mathrm{R} ?=, 80837063 \text { Adjusted R?=,79283311 } \\
F(3,37)=52,027 p<, 00000 \text { Std. Error of estimate: } 10,642\end{array}$} \\
\hline & Beta & $\begin{array}{l}\text { Std.Err. } \\
\text { of Beta }\end{array}$ & B & $\begin{array}{c}\text { Std. Err. } \\
\text { of } B\end{array}$ & $t(37)$ & p-level \\
\hline Intercept & & & 28,2564 & 46,115374 & 4,62056 & 0,000045 \\
\hline Fact (Hwm) & $\overline{0,655919}$ & 9. 0,089231 & 8,7169 & 1,185846 & 7,35078 & 0,000000 \\
\hline Fact (Him) & $-0,152698$ & 80,078665 & $5-10,1226$ & 5,214814 & $-1,94112$ & 0,059890 \\
\hline Fact (Htr) & 0,420306 & 60,085279 & 10,9452 & 2,220757 & 4,92857 & 0,000018 \\
\hline \multicolumn{7}{|c|}{ b) } \\
\hline & \multicolumn{6}{|c|}{$\begin{array}{l}\text { Regression Summary for Dependent Variable: Fuel Consumption } \\
R=, 92534460 \mathrm{R} ?=, 85626263 \text { Adjusted R?= } 84869751 \\
\mathrm{~F}(2,38)=113,19 p<, 00000 \text { Std. Error of estimate: } 9,0944\end{array}$} \\
\hline $\mathrm{N}=41$ & Beta & $\begin{array}{l}\text { Std.Err. } \\
\text { of Beta }\end{array}$ & $B$ & $\begin{array}{c}\text { Std. Err. } \\
\text { of B }\end{array}$ & $t(38)$ & p-level \\
\hline Intercept & & & 18,33154 & 4,507495 & 4,06690 & 0,000231 \\
\hline Run, km & $\overline{0,455196}$ & 0,064962 & 0,25455 & 0,036327 & 7,00709 & 0,000000 \\
\hline Fact (Hwm) & 0,672298 & 0,064962 & 8,93456 & 0,863321 & 10,34906 & 0,000000 \\
\hline & & & c) & & & \\
\hline
\end{tabular}

Fig. 5. Results of cluster analysis and formation of the Multidimensional Model Fuel Consumption (Norma) MLT- 6 as of 2019: a) a dendogram of the relationship with performance indicators; b) Table of parameters of the four-factor model; c) Two-factor model options table.

On the graf, the closer the indicators are to zero, the higher the relationship. The dendogram axis is based on the difference between the unit and the $\mathrm{R}$ correlation ratio, i.e. $\mathrm{K}=(1-\mathrm{R})$. For example, in Figure 5, Fuel Consumption (Fact) is most closely related to Hour Work. A projection on the axis of the diagram of combining variables of $K=0,4$. The level of correlation is defined $\mathrm{R}=(1-\mathrm{K})=0,6$. When selecting the indicators in a multidimensional model, you need to consider and eliminate the impact on the outcome of the multicollinearity property - the presence of linear links between the explaining variables. 
To achieve this goal, only one is selected from the association of highly correlated indicators. On the presented dendogram to strongly correlated indicators $(\mathrm{R}=0,85)$ are pairs: Hour in total $\left(H_{t o t m}\right)$, Fact $\left(H_{w m}\right)$ and Run - Fact $\left(H_{t r m}\right)$.

When forming a multidimensional model in the STATISTICA program, it is possible to eliminate multicollinearity as part of the standard procedure. Figure $5 \mathrm{~b}$ shows the results of identifying three $b_{1}, b_{2}, b_{3}$ parameters of the Fuel Consumption (Norma) model, using the performance indicators in the three modes provided in the traditional method: working mode idling mode, transport mode. The "Beta" column presents paired correlation ratios, and the "B" column shows the identified parameters of the model's multidimensional equation. "Intercept" free member of the equation.The adequacy of the model is high multiple correlation ratio of $\mathrm{R}=0.899$. Fisher's criterion $\mathrm{F}=52$ is more than table (2.8), St. Еггог estimate $=10,6$. To increase the importance of all members of the equation, variables with the highest p-level levels are excluded from their membership. On Figure $5 \mathrm{~b}$, this is Fact $\left(H_{i m}\right)$. To increase adequacy in the model instead of the indicator of the time of operation in transport mode - Fact $\left(H_{t r m}\right)$ introduced the indicator Run, km. In Figure $5 \mathrm{c}$ shows the final two-factor model. The adequacy of the model has increased - multiple correlation ratio of $\mathrm{R}=0,925$. Fisher's Criterion $\mathrm{F}=113$ more table (3,2), St. Еггог estimate 9,09 .

According to the parameters of the two-factor model in Figure 3, the implementation of Predicted $2 \mathrm{f}$ Fuel Consumption, $\mathrm{kg}$, which is chosen as a normative one, is built. The values of this implementation allow:

- to use it to assess fuel efficiency in travel when the working time and run of the SSPS are variationd;

- to filter the "emissions" of fuel consumption in the database and to record unauthorized fuel consumption.

In this example (figure 3), a correction of the fuel consumption indicator is made, which should be spent based on the MLT-6 modes of operation. In the period 16.06.2019 the norm should be $114 \mathrm{~kg}$, in the period 25.06 .2019 the norm should be $111 \mathrm{~kg} ; 30.06 .2019-20 \mathrm{~kg}$.

Thus, only three trips can be detected fuel overruns of $565 \mathrm{~kg}$. At an average monthly consumption of $1,800 \mathrm{~kg}$, unauthorized fuel overruns are at least $30 \%$. The error of the resulting model relative to Fuel Consumption (Fact) is defined as MAPE $=8 \%$, which indicates.

\section{Conclusions}

1. Analytically, it has been established that the SSPS method provides for the use of only the value of the hours of fuel. Techniques do not include analysis of other indicators of his work, such as Run, km.

2. It is proposed to apply the identification method based on the use of additional operating indicators and actually measured fuel consumption values to form rationed fuel consumption values.

3. In the proposed methodology, rationed fuel consumption values are formed as a model from the planned performance and parameters of their relationship with actual fuel consumption. Model parameters are calculated based on a multi-factor equation solution.

4. The most informative performance indicators are Run and working time. Using these metrics, the normalized fuel consumption model achieves the lowest margin of error (no more than $10 \%$.)

5. Using reasonable rationed fuel consumption values can reduce fuel consumption by eliminating unauthorized overruns by more than $30 \%$. 


\section{References}

1. American association of railroads, 2014 Q4 base, Washington, DC: AAR (2015)

2. J. HE, W. WU, Y. XU, Journal of Transportation Systems Engineering and Information Technology, 10, 5, 22-27 (2010)

3. M. Abas, Z. Abidin, S., Rajoo, et al., SAE Technical Paper, 2017-01-0986 (2017)

4. C. Dimitrios, C. D. Rakopoulos, E. G. Giakoumis, et al., Energy, 43, 214-234 (2012)

5. H. An, W.M Yang, A. Maghbouli, et al., Applied energy., 112, 493-499 (2013)

6. Ismet Sezer, Thermal Sciences, 50,1594-1603 (2011)

7. Zhu I. Cheung CS, Zhang WG, Huang Z, Fuel., 90, 1743-50 (2011)

8. Ngoya $\mathrm{T}$ shizanga, South African Journal of Chemical Engineering, 23, 145-156 (2017)

9. D.Capuano, 2017. Renewable and Sustainable Energy Reviews. 69, 759-770.

10. A.V. Gritsenko, K. V. Glemba, A. A. Petelin, Journal of King Saud University Engineering Science https://doi.org/10.1016/j.jksues.2019.12.001

11. IEA, Transport, Energy and CO2 (IEA, Paris, 2009)

12. C.-J. Winter, Int. J. Hydrogen Energy, 34, S1eS52 (2009)

13. A. Hoffrichter, University of Birmingham, Birmingham, Retrieved from (2013) http:// etheses.bham.ac.uk/4345/

14. Fuel Consumption Measurement for Diesel Engines, KRAL AG, 6890, Lustenau, Austria https://www.iberfluid.com/uploads/productos/producto-0243-52686.pdf

15. L. Rymaniak, P. Daszkiewicz, J. Merkisz, Y. Bolzhelarskyi, AIP Conference Proceedings 2078, 020053 (2019) https://doi.org/10.1063/1.5092056

16. A.N. Mitrofanov, G.M. Tretyakov, S.V. Kopeikin, Russian Electrical Engineering, 88, № 3, 109-114 (2017) 